should be performed more frequently on short boys. Though it is debatable that all short boys should have a karyotype, certainly those with any stigmata suggestive of Turner's syndrome, with undescended testes, hypospadias, or with an unacceptable final height warrant one. More aggressive investigation may be necessary as Ayuso et al have reported the case of a phenotypic male with 46 XY karyotype from leukocytic cell lines but in whom the $45 \mathrm{XO}$ cell line was observed in skin fibroblasts and gonadal tissue. ${ }^{2}$ One last issue to consider is proper management of the testes. Obviously if the gonad is intraabdominal, it must be removed as it is likely to be a dysgenetic testis or streak gonad. Dysgenetic testes are presumed to be more prone to neoplastic transformation than streak gonads: Manuel et al calculated a tumour expectancy of over $70 \%$ by the third decade. ${ }^{5}$ It is not clear, however, that palpable, descended testes really have such a high malignant potential. ${ }^{16}$

Testicular biopsy before and after puberty, to detect carcinoma in situ, may be desirable and allow either early orchidectomy or bilateral irradiation if it is found. ${ }^{6}$

1 Simpson JL. Abnormal sexual differentiation in humans. Annu Rev Genet 1982;16:193-224.

2 Ayuso MC, Ramos MC, Bello MC, Jimenez A, Cascos AS, Herrera JE. Cytogenetic and clinical findings in ten 45 , X/46, XY patients. Clin Genet 1984;25:336-40.

3 Hsu LYF. Prenatal diagnosis of $45 \mathrm{X} / 46 \mathrm{XY}$ mosaicism-a review and update. Prenat Diagn 1989;9:31-48.

4 Rosenfeld R, Hintz R, Johanson A, et al. Three-year results of a randomized prospective trial of methionyl human growth hormone and oxandrolone in Turner syndrome. Pediatr 1988;113:393-400.

5 Manuel $M$, Katayama $K$, Jones $H$. The age of occurrence of gonadal tumors in intersex patients with a $\mathrm{Y}$ chromosome. Am F Obstet Gynecol 1976;124:293-300.

6 Muller J. Abnormal infantile germ cells and development of carcinoma-in-situ in maldeveloped testes. Int $f$ Androl 1987;10:543.

\title{
Discovering anaemia at child health clinics
}

\author{
E Marder, A Nicoll, L Polnay, C E Shulman
}

\begin{abstract}
Children at three inner city child health clinics were offered haemoglobin estimation by fingerprick blood test when attending for immunisation against measles. Of the 98 immunised, 92 (94\%) participated in the study, together with 58 other children. Anaemia (haemoglobin concentration $<110$ g/l) was found in 33 of 130 overall (25\%), and in 17 of 44 Asian children (39\%). The method of testing was acceptable to parents and staff.
\end{abstract}

Iron deficiency anaemia is common among toddlers. $^{1}$ The reason is usually dietary, and contributing factors include late weaning, use of ordinary cows' milk, and weaning on to a diet low in iron. It has important effects, including recurrent mild infections, poor weight gain, behavioural problems, and decreased mental performance, all of which may be helped by treatment with iron. ${ }^{2}$

It has been suggested that toddlers should be screened for iron deficiency, ${ }^{3}$ and the recent report of the Joint Working Party on Child Health Surveillance stated that screening for iron deficiency was probably desirable but further research is needed. ${ }^{4}$ The first question is whether routine blood sampling would be acceptable to parents. In this study we have looked at this, together with the feasibility of setting up a screening programme using haemoglobin estimation. We also calculated the incidence of anaemia in our community.

\section{Subjects and methods}

The study population comprised all children Accepted 1 March 1990 who were due to receive immunisation against measles and were aged 15-24 months during the six month study period. ${ }^{5}$

Invitation to participate was by letter accompanying the reminder about the immunisation appointment for children attending two of the clinics or by asking the parents when children attended for immunisation at the third. Facilities were available to explain the study to parents in various Asian languages. Signed parental consent was obtained. Children with known haematological disorders or diseases associated with anaemia were excluded.

We recognised that the study might have a detrimental effect on the measles immunisation rate. This was monitored during the study and it was decided to stop the study if an appreciable decrease occurred.

Capillary blood samples were taken by fingerprick, collected in $1 \mathrm{ml}$ EDTA bottles and sent by routine collection to the hospital laboratory. Haemoglobin concentration (normal $\geqslant 110 \mathrm{~g} / \mathrm{l}$ ) mean corpuscular volume (normal 76-100 fl), and mean corpuscular haemoglobin (normal 27-33 pg) were measured.

A haemoglobin concentration of $<110 \mathrm{~g} / \mathrm{l}$ was considered as indicating anaemia, and the parents of these children were asked to attend the clinic and were given dietary advice (with the aid of the community dietician). Those with haemoglobin concentrations of $<95 \mathrm{~g} / 1$ were given oral iron supplements and further investigations including electrophoresis and estimation of serum ferritin concentration undertaken. All anaemic children were followed up to ensure that they responded to diet or iron. If another cause of anaemia or lack of response was found, appropriate follow up was arranged.

The study was undertaken with the usual 
Table 1 Number (\%) of children by ethnic group

\begin{tabular}{|c|c|c|c|}
\hline & \multicolumn{2}{|l|}{ Anaemic } & \multirow{2}{*}{$\begin{array}{l}\text { Not anaemic } \\
(\text { haemoglobin } \geqslant 110 \mathrm{~g} / \mathrm{l})\end{array}$} \\
\hline & $\begin{array}{l}\text { Haemoglobin } \\
<95 \mathrm{~g} / \mathrm{l}\end{array}$ & $\begin{array}{l}\text { Haemoglobin } \\
95-110 \mathrm{~g} / \mathrm{l}\end{array}$ & \\
\hline $\begin{array}{l}\text { White }(n=67) \\
\text { Afro-Caribbean }(n=15) \\
\text { Asian }(n=44) \\
\text { Mixed race }(n=4)\end{array}$ & $\begin{array}{l}2(3) \\
1(7)^{*} \\
7(16) \dagger \\
0\end{array}$ & $\begin{array}{r}9(13) \\
2(13) \\
10(23) \\
2(50)\end{array}$ & $\begin{array}{r}56(84) \\
12(80) \\
27(61) \\
2(50)\end{array}$ \\
\hline Total $(n=130)$ & $10(8)$ & $23(18)$ & $97(75)$ \\
\hline
\end{tabular}

*This child had sickle cell anaemia.

tIncudes one child with thalassaemia trait.

Table 2 Number (\%) of Asian and non-Asian children according to severity of anaemia

\begin{tabular}{|c|c|c|}
\hline & $\begin{array}{l}\text { Asian children } \\
(n=44)\end{array}$ & $\begin{array}{l}\text { Non-Asian children } \\
(n=86)\end{array}$ \\
\hline $\begin{array}{l}\text { Haemoglobin } \\
\geqslant 110 \mathrm{~g} / 1 \\
<110 \mathrm{~g} / 1\end{array}$ & $\begin{array}{l}\text { n: } \\
27(61) \\
17(39)\end{array}$ & $\begin{array}{l}70(81) \\
16(19)\end{array}$ \\
\hline
\end{tabular}

clinic staff. No additional staff or hours were used. Approval was obtained from the local ethics committee.

\section{Results}

A total of 185 children attending two clinics were sent immunisation reminders with letters about the study, and 98 (53\%) subsequently attended; 92 (94\%) participated in the study. The reasons given for non-participation were: no time to wait at the clinic until a doctor was available to do the blood test $(n=2)$; parents confident that the child was not anaemic $(n=1)$; language difficulties prevented proper explanation $(n=1)$; and parents unwilling to subject the child to a blood test $(n=2)$.

A further 58 children were recruited when attending the third clinic for immunisation, making a total of 150 samples taken. Twenty (13\%) were not analysed because of sampling errors (mislabelled, specimen clotted, or insufficient blood taken), so the total number of samples analysed was 130 .

The results are shown according to the severity of anaemia, and ethnic origin (table 1). Thirty three children (25\%) were anaemic $(95 \%$ confidence interval 17.9 to $32.9 \%$ ). In all these children iron deficiency was suggested by low mean corpuscular volume or mean corpuscular haemoglobin, or both, except in one child who had sickle cell anaemia. Further tests were done on many of the children and one child was diagnosed as having thalassaemia trait. No other abnormalities were recorded, though the data collection was not complete.

There was no difference in the incidence of anaemia between the white and Afro-Caribbean subgroups (Fisher's exact probability 0.76). These two were combined and Asian and nonAsian children compared (table 2). This shows that $17(39 \%)$ of Asian children were anaemic compared with $16(19 \%)$ of non-Asians $\left(\chi^{2} 6 \cdot 17\right.$, $\mathbf{p}=0 \cdot 01$ ).

\section{Discussion}

In the two clinics in which participation was invited by letter we were disappointed that only $53 \%$ of those invited attended for immunisation during the study period. This rate was similar to areas in the city where the study was not being carried out, so we did not feel that the study itself caused the low response. A number of those invited attended late-that is, well after the study period had finished-and so could not be included. Indeed, a recent study in the same clinics in Nottingham showed that immunisation uptakes seem to be low in the immediate period after immunisation is due (only $5 \%$ primary immunisation completed by the end of the 15th month) but continue to rise appreciably over the following years, so that when latecomers are included, uptake rates are much higher. ${ }^{5}$

We are aware that this low response rate is likely to render our study population unrepresentative of the community as a whole, because we have excluded latecomers and nonattenders. According to inverse care laws, the non-attenders may include the most anaemic children. The rates we found, therefore, may well be a conservative estimate.

The test was popular with parents and uptake rate among attenders for immunisation was high (94\%). We were, in addition, requested by many parents to test children who were not part of the study population (elder siblings and toddlers attending clinic for reasons other than immunisation). The sampling procedure did not seem to distress the children unduly.

Staff were asked if there were any problems in administering the programme, and the only ones identified were the time taken in clinic, and sampling errors. As previously stated, testing was within routine clinics and was done by the clinic doctor. Sometimes this resulted in unaccustomed delays in the clinic. Fingerprick blood sampling is a simple technique and could be carried out by health visitors or clinic nurses, either in existing clinics or on other occasions, thus spreading the workload and decreasing delays during routine clinics.

We were concerned at the number of sampling errors (13\%), largely insufficient blood or clotted samples. Consultation with our hospital laboratory, however, suggested that this was not unusual for capillary samples. The frequency of these errors decreased as we became familiar with the blood sampling technique.

The results showed a high incidence of anaemia in the second year of life $(25 \%)$ and particularly in the Asian population (39\%). These are similar to findings from Birmingham, ${ }^{2}$ and somewhat higher than in Bristol. ${ }^{6}$

Our study shows that screening within com- 
munity child health clinics is feasible, and furthermore that routine blood-sampling is acceptable to parents, so answering the first question posed in Health for all Children. ${ }^{4}$ The second question put by this document was whether the incidence of iron deficiency could be reduced by appropriate health education. This remains to be answered. The third question was 'what measurable benefits may result from a more aggressive approach to the identification and treatment of iron deficiency?' Although problems associated with iron deficiency have been identified and shown to respond to treatment with iron, the natural history of iron deficiency anaemia in childhood is not understood. It may be that deficiency resolves with age, or recurs after a period of treatment.

Considering the incidence, importance, and reversibility of iron deficiency anaemia it seems clear that intervention is necessary. Estimation of haemoglobin concentration by fingerprick is feasible in the community, and acceptable to parents. Evaluation is not yet complete enough to formulate a nationwide policy. The results of our study, however, justify special consideration for high risk subgroups in the meantime.

We thank the following for help with the study: $\mathrm{Dr} R$ Dove, Dr J Swann, clerical staff, health visitors, and clinic nurses at Radford, Mary Potter, and Forest Fields child health clinics, Dr J Pearson for statistical advice, community dieticians, staff of the haematology laboratory at the Queen's Medical Centre, and the University of Nottingham Medical School Trustees.

1 Erhardt $P$. Iron deficiency in young Bradford children from different ethnic groups. $\mathrm{Br}$ Med $\mathcal{f}$ 1986;292:90-3.

2 Aukett MA, Parks YA, Scott PH, Wharton BA. Treatment with iron increases weight gain and psychomotor development. Arch Dis Child 1986;61:849-57.

3 Anonymous. Iron deficiency - time for a community campaign. [Editorial.] Lancet 1987;i:171-2.

$4 \mathrm{Hall} \mathrm{MB}$, ed. Health for all children. Oxford: Oxford Medical Publications, 1989:34-6.

5 Polnay $\mathbf{L}$, Horn $\mathbf{N}$. Immunisation practice in an inner city clinic. Health Trends 1989;21:20.

6 James J, Lawson P, Male P, Oakhill A. Preventing iron deficiency in preschool children by implementing an educational and screening programme in an inner city practice. $\mathrm{Br}$ Med $\mathcal{f}$ 1989;299:838-40.

\title{
Diagnosis of neonatal chlamydial conjunctivitis
}

\author{
G Phillips, J S Forsyth, I A Harper
}

\begin{abstract}
Fifty seven babies with ophthalmia neonatorum had conjunctival smears examined by microscopy and bacterial culture, and by immunofluorescence, to find out which was the best method of diagnosing chlamydial conjunctivitis. The positive (33\%) and negative $(\mathbf{7 0} \%)$ predictive values of microscopy and culture were too low for us to accept it as an adequate method of detecting the presence of Chlamydia trachomatis.
\end{abstract}

Chlamydia trachomatis is a common cause of generally benign ophthalmia neonatorum. ${ }^{1}$ It may also cause pneumonia. ${ }^{2}$ The mother's genital tract is infected and she may develop ascending infection, pelvic inflammatory disease, and (perhaps) infertility. The costs of chlamydial infections in the United States have been estimated at more than $\$ 1.4$ billion a year; much of this is for the treatment of pelvic inflammatory disease. ${ }^{3}$ Sexual contacts of the mother, if untreated, may spread infection.

Winceslaus and colleagues diagnosed chlamydial ophthalmia neonatorum using simple laboratory techniques, which are valuable in laboratories lacking diagnostic facilities for chlamydial infection. ${ }^{4}$ We have evaluated similar simple techniques using immunofluorescence for comparison (MicroTrak Chlamydia trachomatis direct fluorescent antibody reagent, Syva UK).

\section{Patients and methods}

Fifty seven babies between 1 and 42 days old in hospital with acute conjunctivitis were studied; 51 were less than 21 days old. None had received topical antibiotics.

After removing any exudate, two swabs were firmly taken from the inflamed tarsal conjunctivas. One swab was rolled on to the unmasked area of a microscope slide (Syva UK), allowed to dry, then fixed with acetone.

Another ordinary smear was made from this swab. The second swab was sent in Stuart's transport medium for bacterial culture. Specimens were sent as soon as possible. Masked slides were stained, either on arrival in the laboratory or after overnight storage at $4^{\circ} \mathrm{C}$ (or at $-20^{\circ} \mathrm{C}$ if longer storage was required).

\section{LABORATORY METHODS}

Staining of slides by immunofluorescence Firstly, $25 \mu \mathrm{l}$ of MicroTrak direct specimen stain reagent (Chlamydia trachomatis-direct fluorescent antibody reagent) were added to the unmasked area of the slide. This was incubated at room temperature for 15 minutes, then rinsed, and mounted with MicroTrak mounting fluid.

The preparation was examined for chlamydial particles by incident light fluorescence and a $\times 50$ water immersion fluorescence objective.

Giemsa staining of slides

Slides were fixed with methyl alcohol, stained with Giemsa stain, and examined by light microscopy using a $\times 54$ oil immersion or $\times 100$ oil immersion objective, for the presence of any polymorphonuclear leucocytes and bacteria. 